Internist 2021 - 62 (Suppl 4):\$496

https://doi.org/10.1007/s00108-021-01141-7

Online publiziert: 26. August 2021

(c) Springer Medizin Verlag $\mathrm{GmbH}$, ein Teil von

Springer Nature 2021

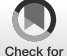

\section{Erratum zu: 64/m mit progredienter Dyspnoe und vermehrten Exazerbationen bei chronisch obstruktiver Lungenerkrankung}

Redaktion "Der Internist"

Springer Medizin Verlag GmbH, Heidelberg, Deutschland

\section{Erratum zu:}

Der Internist 2021

https://doi.org/10.1007/s00108-021-

01111-z

Die Online-Version dieses Artikels, veröffentlicht am 03. August 2021, enthielt leider Übersetzungsfehler. Diese wurden korrigiert.

Wir entschuldigen uns für den Fehler.

Die Redaktion

\section{Korrespondenzadresse}

Redaktion "Der Internist“

Springer Medizin Verlag $\mathrm{GmbH}$

Tiergartenstraße 17, 69121 Heidelberg,

Deutschland
Die Online-Version des Originalartikels ist unter https://doi.org/10.1007/s00108-021-01111-z zu finden.

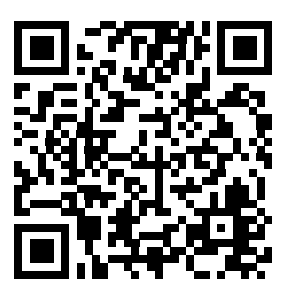

QR-Code scannen \& Beitrag online lesen 